\title{
STUDI PENANGGULANGAN BANJIR DI KALI BATAN KABUPATEN KEDIRI
}

\author{
Moch Adib Kuncoro', Sigit Winarto ${ }^{2}$, Yosef Cahyo SP . \\ ${ }^{1,2,3}$ Fakultas Teknik, Universitas Kadiri. \\ e-mail: ${ }^{1}$ adibkuncoro@gmail.com, ${ }^{2}$ sigit.winarto@unik-kediri.ac.id, \\ 3 yosef.cs@unik-kediri.ac.id.
}

\begin{abstract}
Kali Batan is one of the tributaries of the Brantas River, which is located in the Kediri Regency. In the last few years, there have been floods in Kali Batan. In the Batan watershed, there are three stations that are considered to represent the percentage of the effect of the calculation of the maximum daily rainfall intake, which is $83.11 \mathrm{~mm}$. From the maximum daily rainfall, the result is-0.9546. From the calculations in the Smirnov-Kolmogorov method distribution suitability test, it shows that the highest value of $\Delta_{\max }$ is $=0.126$, with $\alpha=5 \%$ and $n=20$, the value $\Delta_{\text {critical }}=0.304$. So it can be concluded that $\Delta_{\max }<\Delta_{\text {critical }}$ so that the Log Pearson type III distribution can be accepted. From the measurement of the Batan watershed at the upstream review point, the result is $3.206 \mathrm{~m}^{3} / \mathrm{s}$. From the measurement of the Kali Batan watershed at the downstream point, the results obtained were 202.475, using equations (2-14) to (2-17), the design flood hydrograph obtained $3,825 \mathrm{~m}^{3} / \mathrm{s}$. The value of the net rainfall intensity value (25 years) entered into the coordinates of the Nakayasu Synthetic Hydrograph, then the flood discharge design $Q_{25 t h}$ is obtained.
\end{abstract}

Keywords : Flood, Flood Prevention Studies, Batan River, Rain

\begin{abstract}
Abstrak
Kali Batan merupakan salah satu anak sungai Kali Brantas yang terletak di Kabupaten Kediri. Beberapa tahun terakhir terjadi banjir di Kali Batan. Pada DAS Batan terdapat tiga stasiun penakar hujan yang dianggap mewakili dengan prosentase pengaruh perhitungan pengambilan curah hujan harian maksimum didapatkan sebesar $83,11 \mathrm{~mm}$. Dari curah hujan harian maksimum didapatkan hasil- 0,9546. Dari perhitungan pada Uji kesesuaian distribusi metode Smirnov-Kolmogorov menunjukkan bahwa nilai tertinggi $\Delta_{\max }$ adalah $=0,126$, dengan $\alpha=5 \%$ dan $\mathrm{n}=20$ didapatkan harga $\Delta_{\text {kritis }}=0,304$. Maka dapat disimpulkan bahwa $\Delta_{\max }<\Delta_{\text {kritis }}$ sehingga distribusi Log Pearson tipe III dapat diterima. Dari pengukuran DAS Batan pada titik tinjau hulu didapatkan hasil3,206 $\mathrm{m}^{3} / \mathrm{dt}$. Dari pengukuran DAS Kali Batan pada titik hilir didapatkan hasil202,475, denganmenggunakan persamaan-persamaan (2-14) sampai dengan (2-17), hidrograf banjir rancangan diperoleh $3,825 \mathrm{~m}^{3} /$ dt.Besarnya nilai intensitas curah hujan netto (kala ulang 25 th) dimasukkan ke dalam koordinat Hidrograf Sintetis Nakayasu maka didapatkan debit banjir rancangan $\mathrm{Q}_{25 \text { th. }}$.
\end{abstract}

Kata Kunci : $\quad$ Banjir, Studi Penanggulangan Banjir, Kali Batan, Hujan 


\section{PENDAHULUAN}

Banjir bukan merupakan persoalan selama kejadian tersebut tidak menimbulkan persoalan bagi kehidupan manusia. Namun sejak berkembangnya permukiman dan berbagai kegiatan usaha di dataran banjir (flood plain), persoalan banjir menjadi ada. Sejak itu pula upaya untuk mengurangi kerugian yang disebabkan oleh banjir dimulai, [1].

Kali Batan merupakan salah satu anak sungai Kali Brantas yang terletak di Kabupaten Kediri. Kali Batan memiliki luas Daerah Pengaliran seluas $25 \mathrm{~km}^{2}$, dengan alur sungai sepanjang 17,25 km membentang dari Desa Badas Kecamatan Badas hingga Desa Purwoasri, Kecamatan Purwoasri. Beberapa tahun terakhir terjadi banjir di Kali Batan. Beberapa desa yang rawan terkena imbas dari banjir tersebut antara lain Desa Tenggerlor, Kapi, Kapas, Kunjang, Klepek, Belor, Ketawang, Mojokerep dan Puhjajar.

Dampak dan akibat jika banjir di kali batan terjadi adalah merosotnya hasil panen di kawasan wilayah kali batan, karena kali batan mengaliri hampir semua sawah para petani yang memasok hasilnya di pasar badas, jika banjir terjadi maka akan terjadi kelumpuhan di beberapa pasar di wilayah tersebut, .

Berangkat dari latar belakang masalah di mana diperlukan perencanaan perbaikan alur Kali Batan sebagai upaya penanggulangan banjir maka permasalahan dapat dirumuskan sebagai berikut :

1. Berapa debit banjir rancangan sebagai dasar evaluasi kapasitas debit Kali Batan dan sebagai dasar perencanaan perbaikan alur Kali Batan ?

2. Bagaimana kondisi hidrolik aliran debit banjir rancangan pada kondisi alur existing Kali Batan?

3. Bagaimana stabilitas penampang yang ada di Kali Batan ?

4. Bagaimana analisis dan perencanaan alur Kali Batan agar mampu mengalirkan debit banjir rancangan dengan aman?

Agar permasalahan tidak meluas maka dalam studi ini permasalahan dibatasi sebagai berikut ini :

1. Analisa hidrologi untuk menentukan debit banjir rancangan sebagai dasar perbaikan sungai.

2. Analisa hidrolika untuk mengetahui kondisi muka air debit banjir rancangan pada alur existing dan setelah perbaikan.

3. Analisa untuk menanggulangi banjir di kali batan.

4. Analisa stabilitas tebing sungai terhadap longsor.

5. Tidak membahas masalah sosial yang timbul akibat perencanaan perbaikan alur sungai.

6. Tidak membahas masalah ekonomi berkaitan dengan pembiayaan terhadap perencanaan perbaikan alur sungai. 
7. Data curah hujan dari tahun 1997 sampai 2016 dari UPTD Kandangan, Badas, Kunjang.

8. Data debiet Kali Batan dari tahun 2005 - 2015 UPTD PUPR Kunjang.

Tujuan dari studi ini adalah untuk mendapatkan perencanaan perbaikan alur Kali Batan agar dapat mengalirkan debit banjir dengan aman, [2]. Dengan tujuan tersebut maka dari studi ini dapat diketahui:

1. Untuk mengetahui cara menanggulangi jika terjadi banjir di kali batan.

2. Untuk menjadi gambaran perbaikan terhadap kurang optimalnya pengawasan.

3. Untuk menambah kesigapan pemerintah dalam menjalankan tugasnya di pengairan.

4. Dapat menjadi refrensi skripsi yang akan datang.

Manfaat dari studi ini adalah untuk memberikan masukan terhadap upaya teknis guna menanggulangi terjadinya bencana banjir pada Kali Batan, [3].

\section{METODE PENELITIAN}

\subsection{Deskripsi Area Studi}

Kali Batan merupakan salah satu anak sungai Kali Brantas yang berada di wilayah Kabupaten Kediri. Sungai ini memiliki panjang \pm 17 km membentang dari Kecamatan Kandangan hingga sampai area Kecamatan Purwoasri. Secara administratif Kali Batan melingkupi enam kecamatan, yaitu Kecamatan Kandangan, Pare, Plemahan, Kunjang, Papar dan Purwoasri. Sedangkan secara geografis terletak antar $112^{\circ} 05^{\prime} 00^{\prime \prime}-112^{\circ} 15^{\prime} 00^{\prime \prime}$ BT dan $7^{\circ} 38^{\prime} 15^{\prime \prime}-7^{\circ} 45^{\prime} 15^{\prime \prime}$ LS.

\subsection{Tahapan Penelitian}

Untuk mendapatkan hasil studi dilakukan tahapan penelitian antara lain sebagai berikut [4][5]:

1. Pengumpulan data

2. Analisa hidrologi.

3. Evaluasi kapasitas debit sungai existing.

4. Analisa dan perhitungan dimensi alur sungai rencana.

5. Evaluasi stabilitas tebing sungai rencana.

\subsection{Pengumpulan Data}

Pengumpulan data dilakukan dengan dua cara, yaitu data primer dan data sekunder. Data primer adalah data yang dikumpulkan sendiri oleh penulis dengan cara melakukan investigasi ke lapangan. Sedangkan data sekunder adalah data yang telah dipublikasikan atau data yang diperoleh dari instansi yang berkompeten, [6]. 
Pengumpulan data primer bersifat fakultatif jika data tersebut bersifat penting terhadap hasil studi dan tidak dapat diperoleh dari instansi yang berkompeten.

Data-data yang dibutuhkan dalam studi ini antara lain :

a. Peta rupa bumi.

b. Data curah hujan.

c. Data karakteristik Daerah Pengaliran Sungai.

d. Data penampang sungai.

e. Data karakteristik lapisan tanah pada alur sungai, [7][8].

\subsection{Analisa Hidrologi}

Analisa hidrologi merupakan salah satu bagian dari keseluruhan rangkaian dalam perencanaan bangunan air seperti sistem drainase, gorong-gorong, tanggul penahan banjir dan sebagainya. Analisa hidrologi diperlukan untuk pengumpulan informasi penting sebagai masukan untuk analisa selanjutnya.

Analisa hidrologi dilakukan untuk mengkonversi data curah hujan harian menjadi data debit banjir rancangan yang akan dijadikan acuan untuk mengevaluasi kapasitas debit sungai existing. Selain itu debit banjir rancangan juga berfungsi sebagai acuan untuk melakukan perbaikan alur sungai, [9][10][11].

Dalam perancangan terdapat beberapa faktor yang memliki pengaruh besar. Faktorfaktor tersebut antaran lain :

1. Faktor Sosial Ekonomi

2. Faktor Politik

3. Faktor Teknis

4. Faktor Estetika

Sedangkan dalam perencanaan saluran sungai kita harus memperhatikan faktor-faktor kapasitas pengaliran, kapasitas saluran, kecepatan aliran, bahan konstrksi saluran kemiringan dasar saluran untuk penampang. Jenis saluran yang digunakan adalah saluran terbuka berdasarkan aliran seragam. Aliran seragam (uniform flow) dianggap memiliki ciri-ciri pokok sebagai berikut:

a. Kedalaman, luas basah, kecepatan dan debit setiap penampang pada saluran yang lurus adalah konstan.

b. Garis energy, muka air dasar dan dasar saluran sejajar, besar kemiringannya sama

\subsection{Evaluasi Kapasitas Debit Sungai Exsiting}

Evaluasi kapasitas debit sungai existing dilakukan dengan acuan debit banjir rancangan. Evaluasi ini dilakukan karena Kali Batan adalah sungai alami sehingga tidak ada keseragaman 
penampang. Jika alur sungai existing secara hidrolis tidak mampu mengalirkan debit banjir rancangan maka perlu dilakukan perbaikan alur sungai, [12][13].

Debit/Banjir Rancangan adalah besarnya debit banjir yang ditetapkan sebagai dasar penentuan kapasitas dalam mendimensi bangunan-bangunan hidraulik (termasuk bangunan di sungai), sedemikian hingga kerusakan yang dapat ditimbulkan baik langsung maupun tidak langsung oleh banjir tidak boleh terjadi selama besaran banjir tidak terlampaui.

Untuk menentukan banjir rancangan, apabila data debit di daerah yang dikehendaki sudah mencukupi maka dapat langsung digunakan untuk menentukan banjir rancangan dengan analisis frekuensi. Sedangkan apabila pada daerah tersebut data debit sangat terbatas maka digunakan data hujan

\subsection{Analisa Dimensi Alur Sungai Rencana}

Analisa dan perhitungan dimensi alur sungai rencana dilakukan untuk mendapatkan penampang sungai yang secara hidrolis mampu mengalirkan debit banjir rancangan, [14][15]. Dalam analisa ini dilakukan perbaikan alur sungai yang meliputi normalisasi alur sungai dan perhitungan ketinggian tangkis jika diperlukan penangkisan. Dalam studi ini analisa dimensi alur sungai rencana dihitung dengan Program Hec-Ras, [16][17].

Dalam menentukan bentuk dan dimensi saluran yang akan digunakan dalam pembangunan saluran baru maupun dalam kegiatan perbaikan penampang saluran yang sudah ada, salah satu hal penting yang perlu dipertimbangkan adalah ketersediaan lahan. Mungkin di daerah pedesaan membangun saluran dengan kapasitas yang besar tidak menjadi masalah karena banyaknya lahan yang kosong, tapi di daerah perkotaan yang padat tentu bisa menjadi persoalan yang berarti karena terbatasnya lahan.

Dimensi saluran harus mampu mengalirkan debit rencana atau dengan kata lain debit yang dialirkan harus sama atau lebih besar dari debit rencana. Untuk mencegah muka air ke tepi (meluap) maka diperlukan adanya tinggi jagaan pada saluran, yaitu jarak vertikal dari puncak saluran ke permukaan air pada kondisi debit rencana.

Bentuk penampang saluran pada muka tanah umumnya ada beberapa macam antara lain; bentuk trapesium, empat persegi panjang, segitiga, setengah lingkaran. Selain bentuk tersebut, masih ada bentuk-bentuk penampang lainnya yang merupakan kombinasi dari bentukbentuk tersebut, misalnya kombinasi antara empat persegi panjang dan setengah lingkaran, yang mana empat persegi panjang pada bagian atas yang berfungsi untuk mengalirkan debit maksimum dan setengah lingkaran pada bagian bawah yang berfungsi untuk mengalirkan debit minimum.

Beberapa factor yang harus diperhatikan dalam perhitungan dimensi saluran :

1. Kemiringan Saluran. Kemiringan memanjang saluran dasar biasanya diatur dengan keadaan tinggi topografi dan tinggi energy yang diperlukan untuk mengalirkan air.Dalam berbagai 
hal, kemiringan ini dapat pula bergantung pada kegunaan saluran. Factorfaktor yang perlu dipertimbangkan dalam penentuan kemiringan ialah cara pembangunan, kehilangan akibat rembesan, perubahan iklim dan ukuran saluran.

2. Kapasitas Pengaliran. Dalam perencanaan saluran, periode ulang yang digunakan tergantung fungsi saluran serta daerah tangkap hujan yang dikeringkan.Penentuan periode ulang juga didasarkan dengan pertimbnganpertimbangan ekonomis.

3. Kapasitas Saluran

4. Koefisien Kekasaran Manning

\subsection{Evaluasi Stabilitas Tebing Rencana}

Mengingat bahwa salah satu permasalahan pada lokasi studi adalah terjadinya kelongsoran tebing, maka perlu dilakukan evaluasi stabilitas tebing alur sungai terhadap perbaikan alur sungai rencana. Hal ini dimaksudkan agar hasil perencanaan tidak menimbulkan masalah baru yaitu terjadinya longsoran tebing yang pada akhirnya menyebabkan sedimentasi pada alur sungai, [18][19].

Dalam studi ini analisa stabilitas tebing sungai rencana dihitung dengan Program PSlope, [20].

\section{HASIL DAN PEMBAHASAN}

\subsection{Rerata Curah Hujan Harian Maksimum}

Pada DAS Batan terdapat tiga stasiun penakar hujan yang dianggap mewakili, yaitu Stasiun Kencong, Badas dan Kunjang, dengan prosentase pengaruh sebagai berikut :

Rerata curah hujan harian daerah maksimum yang digunakan adalah harga maksimum dari hasil perhitungan diatas. Pada tahun 2001 didapatkan harga sebesar 83,11mm.

\subsection{Distribusi Log Pearson Tipe III}

Dari data curah hujan harian maksimum DAS Batan, dilakukan perhitungan distribusi Log Pearson III, dengan menggunakan persamaan (2-3) sampai dengan (2-6) maka didapatkan hasil perhitungan - 0,9546.

Sehingga didapatkan persamaan distribusi frekuensi sebagai berikut :

$\log \mathrm{X}_{\mathrm{T}}=\overline{\log X}+S d . G$

$\log \mathrm{X}_{\mathrm{T}}=1,859+0,1135 . \mathrm{G}$

Dari persamaan diatas didapatkan curah hujan rancangan $\left(\mathrm{X}_{\mathrm{T}}\right)$ untuk berbagai kala ulang dimana $\mathrm{G}$ didapat berdasarkan harga koefisien kepencengan (Cs) serta tingkat probabilitasnya 


\subsection{Uji Kesesuaian Distribusi}

Pemeriksaan uji kesesuaian ini dimaksudkan untuk mengetahui suatu kebenaran hipotesa distribusi frekuensi. Dengan pemeriksaan uji ini akan diketahui:

1. Kebenaran antara hasil pengamatan dengan model distribusi yang diperoleh secara teoritis.

2. Kebenaran hipotesa diterima atau ditolak.

Dalam studi ini uji distribusi yang digunakan adalah uji Smirnov Kolmogorov dan uji Chi Kuadrat.

\subsection{Uji Smirnov Kolmogorov}

Perhitungan menunjukkan bahwa nilai tertinggi $\Delta_{\max }$ adalah $=0,126$. Sedangkan diketahui bahwa dengan $\alpha=5 \%$ dan $\mathrm{n}=20$ didapatkan harga $\Delta_{\text {kritis }}=0,304$. Maka dapat disimpulkan bahwa $\Delta_{\max }<\Delta_{\text {kritis }}$ sehingga distribusi Log Pearson tipe III dapat diterima.

\subsection{Uji Chi Kuadrat}

Menjumlah seluruh nilai Chi Kuadrat didapatkan nilai $\mathrm{X}^{2}{ }_{\text {hit }}=2,00$. Chi Kuadrat $\left(\mathrm{X}^{2}\right.$ hit $)$ dengan derajad kebebasan 2 dan $\alpha=5 \%$ didapat nilai $X_{\text {cr }}^{2}=5,99$. Maka dapat disimpulkan bahwa $\mathrm{X}_{\text {hit }}^{2}<\mathrm{X}_{\text {cr }}^{2}$, sehingga distribusi yang diuji dapat diterima.

\subsection{Distribusi Hujan Jam - Jaman}

Untuk menghitung hidrograf banjir rancangan dengan hidrograf satuan tertentu perlu diketahui terlebih dahulu distribusi curah hujan jam-jaman dengan interval tertentu. Karena tidak ada alat ukur curah hujan otomatis untuk mengetahui distribusi hujan jam-jaman maka digunakan rumus Mononobe untuk menghitungnya.

Pola distribusi hujan terpusat di Indonesia berkisar antara 4-7 jam setiap harinya dan dalam kajian ini diambil 6 jam. Pembagian curah hujan tiap jam dapat dihitung dengan menggunakan rumus $(2-12)$. Contoh perhitungan :

$\mathrm{t}=6 \mathrm{jam}$

$\mathrm{T}=1 \mathrm{jam}$

$I=\frac{R_{24}}{t}\left[\frac{t}{T}\right]^{2 / 3}=\frac{1}{6}\left[\frac{6}{7}\right]^{2 / 3}=0,55$

Maka dengan cara yang sama didapatkan hasil yaitu sebesar 100,00.

\subsection{Hidrograf Satuan Sintetik}

Dalam kajian ini mengingat bahwa alur sungai yang ditinjau sepanjang 5,00 km, maka perhitungan hidrograf banjir dihitung pada dua titik tinjau, yaitu pada titik hilir (B) dan titik tengah alur sungai tinjauan (A). Debit banjir rancangan yang digunakan sebagai dasar evaluasi kemampuan debit sungai adalah $\mathrm{Q}_{25 \text { th. }}$. 
Dari pengukuran DAS Batan pada titik tinjau hulu didapatkan data Max 165,321. Dari pengukuran DAS Kali Batan pada titik hilir didapatkan data Max 202,475.

\section{KESIMPULAN}

Dari analisa dan memperhitungkan dari berbagai macam hal yang berkenaan dengan penanggulangan banjir di Kali Batan Kabupaten Kediri dalam dapat ditarik kesimpulan bahwa :

Debet awal penampang saluran sebelum di perbaiki/ di normalisasi $Q=1,50 \mathrm{~m} 2$. Dan setelah di lakukan perbaikan/ normalisasi penampang saluran di dapatkan hasil $\mathrm{Q}=3,825 \mathrm{~m} 2$. Kesimpulan dari penjabaran tersebut adalah untuk menanggulangi banjir di daerah kali batan, di perlukan normalisasi aliran sungai sebagai upaya untuk mencegah banjir di Daerah Irigasi Kali Batan, di wilayah UPTD PUPR Badas sampai UPTD PUPR Kunjang.

Usaha - usaha yang dapat di lakukan guna menanggulangi banjir dengan cara perawatan tanggul dan menjaga kebersihan yang intensif. Juga kesungguhan dalam pemeliharaan sarana irigasi dengan dukungan kesadaran para petani dan petugas pemelihara irigasi dalam memanfaatkan sarana tersebut. Dan perlu adanya alokasi dana untuk pembiayaan operasi dan pemeliharaan sarana irigasi yang mulai rusak dan perlu di perbaiki.

Memperhatikan hal-hal tersebut diatas dapat memberikan gambaran nyata begitu pentingnya penanggulangan banjir dan program operasi pemeliharaan di Kali Batan.

\section{SARAN}

Mengingat arti pentingnya studi ini, di harapkan semua pihak yang terkait harus betul betul ikut memelihara dan mempertahankan umur bangunan.

Perlu adanya pendataan yang akurat dan sistematis mengenai keadaan di lapangan yang nantinya di mungkinkan untuk melakukan pengembangan jaringan irigasi dan perbaikanperbaikan yang dirasa perlu. Hal ini harus didukung dengan penambahan tenaga operasional terutama dilapangan agar operasi dan perawatan jaringan irigasi berjalan lancar. Diperlukan kesadaran penuh untuk para pemakai sarana-sarana terutama para petani agar tercipta sistem kerja yang kondusif, [21].

\section{UCAPAN TERIMAKASIH}

Dalam penyusunan artikel ini, penulis ucapkan terimakasih kepada dosen pembimbing dan Universitas Kadiri. Penulis berharap agar artikel ini dapat bermanfaat bagi pembaca. 


\section{DAFTAR PUSTAKA}

[1] J. Loebis, "Banjir rencana untuk bangunan air," 1987.

[2] S. Sosrodarsono, "Perbaikan dan Pengaturan Sungai," 1985.

[3] M. M. A. Shahin, "Statistical Analysis in Hydrology," Intern. Courses Hydraul. Sanit. Eng., 1976.

[4] Departmen Pekerjaan Umum, "pd t-04-2003 Operasi Jaringan Irigasi Teknis.”.

[5] Menteri Pekerjaan Umum, "Peraturan Tentang Pedoman Operasi dan Pemeliharaan Jaringan Irigasi," 2007.

[6] H. A. Sofiyuddin, J. Triyono, and Subari, "PEMBERIAN AIR IRIGASI PADA BUDIDAYA PADI SRI DI MUSIM HUJAN DAN KEMARAU ( STUDI KASUS PETAK TERSIER CMA 5 KI , DI CIRAMAJAYA ,” vol. 1, no. 2, pp. 123-136, 2010.

[7] B. M. Das, N. Endah, and I. B. Mochtar, "Mekanika Tanah Rekayasa Geoteknis ) Braja," Erlangga, Jakarta, 1995.

[8] A. I. Candra, S. Anam, Z. B. Mahardana, and A. D. Cahyono, "Studi Kasus Stabilitas Struktur Tanah Lempung Pada Jalan Totok Kerot Kediri Menggunakan Limbah Kertas,” UKaRsT, vol. 2, no. 2, pp. 88-97, 2018.

[9] A. Wurjanto and D. Sudirman, "Modul Perhitungan Debit Andalan Sungai," Inst. Teknol. Bandung, 2005.

[10] S. Sosrodarsono and K. Takeda, Hidrologi Untuk Pengairan. .

[11] Meliyana, I. Syahputra, A. Mahbengi, and C. Rahmawati, "Studi Penanggulangan Banjir Krueng Tripa,” J. Tek. Sipil Unaya, vol. 4, no. 1, pp. 34-39, 2018.

[12] J. Doorenbos and W. O. Pruitt, "Guidelines for predicting Crop Water Requirement," 1977.

[13] R. G. Allen, L. S. Pereira, D. Raes, and M. Smith, "guidelines for computing crop water requirements," FAO Irrig. Drain. Pap.

[14] I. Subarkah, "Hidrologi Untuk Perencanaan Bangunan Air," 1978.

[15] H. Waluyadi, R. Jayadi, and D. Legono, "Kajian Penanganan Banjir Kali Ciliwung Dki Jakarta Ditinjau Dari Aspek Hidro-Ekonomi,” Forum Tek. Sipil, vol. XVII, no. 3, pp. 643656, 2007.

[16] C. Soemarto, "Hidrologi Teknik," Usaha Nas. Surabaya, 1987. 
[17] L. Sebastian, "PENDEKATAN PENCEGAHAN DAN PENANGGULANGAN BANJIR," Univ. Palembang.

[18] D. K. Kalsim and A. Sapei, “Fisika Lengas Tanah,” Inst. Pertan. Bogor, 1992.

[19] G. H. Kusuma, "Grafili dan Tabel I Perhitungan Beton Bertulang Berdasarkan SKSNI TI 5-199f -03," 1993.

[20] Soedibyo, "Teknik Bendungan," 2003.

[21] A. I. Candra, "Analisis Daya Dukung Pondasi Strauss Pile pada Pembangunan Gedung Mini Hospital Universitas Kadiri,” Ukarst, vol. 1, no. 1, pp. 63-70, 2017. 